\title{
Should Critical Care Professionals Take Hoaxes/Rumours Seriously?
}

\author{
Valentin Nădășan* \\ University of Medicine and Pharmacy Tîrgu Mureș, Department of Hygiene
}

Received: 10 September 2016 / Accepted: 23 September 2016

\section{TO THE EDITOR OF JCCM,}

Thanks to the ever larger penetration of the Internet and especially with the advent of Web 2.0 and social media, hoaxes, rumours and urban legends have become an almost everyday occurrence. While social psychology research contends that rumors can negatively impact on the public by generating distress, intense fear, anxiety, possibly resulting in herd behaviour and violence [1], there is evidence that disease-related rumours may alter health-related behaviors and interfere with medical decision-making [2]. Medical misinformation is most frequently associated with collective emergency situations (e.g., Ebola infected patients refused to be hospitalized because of rumours that international health care workers intentionally brought the virus with them [3]; people from around Kenema, Sierra Leone attacked the hospital after hearing rumours of conspiracy [4]; during the 2011 Fukushima nuclear disaster in Japan, rumours that ingestion of iodized salt could prevent radiation damage lead to a shortage of the product in supermarkets and triggered panic and public unrest [1]) and miracle products or cures that can be commercially exploited [5]. However, there are a number of hoaxes/rumours that probably critical care specialists should neither take lightly as innocuous amusements, nor brush aside with a condescending smile.

\section{1. "Needle can save the life of a stroke patients"}

In short, the message says that anyone can save the life of a stroke victim by pricking his or her fingertips and earlobes with a needle. The "rational" given to support the "technique" is that blood-letting will stop capillaries in the victim's brain from bursting. Then the message goes on to strongly advise the life-saver to wait until the symptoms resolve because rushing the victim to the hospital before the person recovers could result in death or paralysis due to the bursting of the brain capillaries (more details and debunking at www.hoax-slayer. com/needle-stroke.shtml).

\section{2. "How to survive a heart attack when alone"}

Briefly, the message says that many people are alone when experiencing a heart attack and during the few seconds they have left before losing consciousness they should help themselves by coughing repeatedly and very vigorously. Again, there is a "rational" given to support the advice: "deep breaths get oxygen into the lungs and coughing movements squeeze the heart and keep the blood circulating". However, the American Heart Association does not endorse the so-called "cough CPR" (more details and debunking at http:// www.hoax-slayer.com/survive-heart-attack.html).

\section{3. "Cayenne pepper stops heart attack in 60 seconds"}

This message says that a heart attack can be stopped with the simple and awesome power of cayenne pepper, in no more than 60 seconds flat. If the patient is conscious, he should be given a cup of cayenne tea to drink ( 1 teaspoon of cayenne powder in a glass of warm water). In case the patient is unconscious, then a couple of dropperfuls of cayenne tincture or extract should be taken sublingually (details and debunking at http:// thesurvivaldoctor.com/2015/03/23/cayenne-pepperheart-attack/).

And the list could go on. It would be worth mentioning that these hoaxes have not only survived a long time on the English Web but were translated into several other languages, including Romanian. While it is not the aim of this paper to go into a detailed analysis of the psychological and social causes of medical hoaxes, I would still point out three of the most common char- 
acteristics that are linked to their popularity: (a) the use of technical language and elaborate details; (b) the appeal to real or not-so-real medical authorities; and (c) the play on the users' empathy to make them react by forwarding the message.

In conclusion, I would like to address the practical implications of the misinformation phenomenon on the health-related virtual environment. What can health professionals in general, and critical care specialists in particular, do? Although research on social media networks interactions has shown that rational approach is futile with some users [6], there is hope for the more open-minded ones and those willing to rationally approach the topic, to analyze and determine the authenticity of the rumour/hoax [7]. According to the WHO's recommendations, that would practically mean that while continuing their everyday duties in the hospital, critical care specialists could help promptly identify hoaxes and rumors that could cause confusion and mistrust among individuals. They could also engage in a proactive and personal manner, in health education activities, on a community or individual level, in face-to-face setting or on social media, as much as their busy and stressful professional life would allow, in order to address the rumors and prevent unaware individuals from getting hurt [8].

\section{CONFLICT OF INTEREST}

Nothing to declare.

\section{REFERENCES}

1. Zhao L, Wang Q, Cheng J, Zhang D, Ma T, Chen Y, Wang J. The impact of authorities' media and rumor dissemination on the evolution of emergency. Physica A. 2012;391(15):3978-87. doi:10.1016/j.physa.2012.02.004

2. Difonzo N, Robinson NM, Suls JM, Rini C. Rumors about cancer: content, sources, coping, transmission, and belief. J Health Commun. 2012;17(9):1099-115. doi: 10.1080/10810730.2012.665417.

3. Hugonnet S. Ebola diaries: Hitting the ground running. World Health Organization, 2015. Online: http://www.who.int/ features/2015/ebola-diaries-hugonnet/en/

4. Check Hayden E. Infectious disease: Ebola's lost ward. Nature News 2014;513(7519):474-7.

5. Quackery: a $\$ 10$ billion scandal - Hearing before the Subcommittee on Health and Long-Term Care of the Select Committee on Aging, House of Representatives, Ninety-eighth Congress, second session, May 31, 1984. Online: http://www. quackwatch.com/13Hx/pepper_hearing.pdf.

6. UNICEF - Social and Civic Media Section. Tracking antivaccination sentiment in Eastern European social media networks. UNICEF, New York, 2013. Online: http://www.unicef. org/ceecis/Tracking_anti-vaccine_sentiment_in_Eastern_ European_social_media_networks.pdf.

7. Zhao L, Wang J, Huang R. Immunization against the Spread of Rumors in Homogenous Networks. PLoS One. 2015;10(5): e0124978. doi: 10.1371/journal.pone.0124978.

8. WHO. Emergency risk communication training. Module B7: Dynamic Listening and Rumour Management. Online: http:// www.who.int/risk-communication/training/Module-B7. pdf?ua=1. 